\title{
The Challenge in Application of Cryptocurrency as Commodity in Indonesia
}

\author{
Rico Nur Ilham ${ }^{1}$, Khaira Amalia Fachrudin² and Eben Ezer Pakpahan ${ }^{3}$ \\ \{Riconurilham8@gmail.com $\left.{ }^{1}\right\}$ \\ ${ }^{1}$ Doctoral Program, Faculty Economic and Bussiness,University of Sumatera Utara, Indonesia \\ ${ }^{1}$ Faculty of Economic and Bussiness Malikussaleh university Lhokseumawe, Indonesia \\ ${ }^{2}$ Faculty Of Economic and Bussiness, Universitas Sumatera Utara, Indonesia \\ ${ }^{3}$ Doctoral Program, Faculty Economic and Bussiness,Universitas Sumatera Utara, Indonesia \\ ${ }^{3}$ Faculty Social and Political Sciences Universitas HKBP Nomensen Medan, Indonesia
}

\begin{abstract}
Cryptocurrency is a variety of digital currencies and is an asset used as a medium of exchange. This currency uses cryptography and how to make it safe. The system used will create and analyze algorithms and protocols. This prevents no information being changed or interrupted while connected by a third party. Context of digital money, no underlying and unpublished authority. Underlying is the asset used as the basis of the transaction. Based on the international standard of The Accounting and Auditing Organization for Islamic Financial Institutions (AAOIFI), a product is so called if gharar is heavy, exists in non-social business transactions, and on selling objects rather than complementary. virtual money is not a currency. For, if looking at the definition, the currency must be accepted by the public and recognized authority. Digital money is accepted in some circles so it is not a currency. Then the sharf provision (payment) does not apply there because it is not a currency. The purpose of this research is to see the potential of Cryptocurrency whether it can be applied into Digital Asset form only, or even in the future will be an Effect or Comudity. This study uses the Literature study method based on several scientific journals and the theoretical basis related to cryptocurrency and the potential of virtual transactions. The results of this study indicate that the cryptocurrency can be categorized as a virtual product commodity in Indonesia that already has Legal Basis and Legislative regulation. It is hoped that research in this regard will have a positive impact on the development of cryptocurrency in Indonesia, so that later regulation can be made about the cryptocurrency transaction model in Indonesia that has legal force and clear regulation to be applied in the cryptocurrency management.
\end{abstract}

Keywords: Cryptocurrency, Implementation Obstacle of Virtual Commodity Transaction, Regulation

\section{Introduction}

Crypto currency can be used as a payment tool and a means to trade goods and services in Indonesia.The Law No.7/2011 on the Currency states (Law of The Republic of Indonesia Number 7 Year 2011, 2011) that everyone is required to use and accept Rupiah in paper and metals as the legal payment tool in Indonesia.The sanction for this criminal violation is a maximum imprisonment of 1 (one) year and a maximum fine of Rp200,000,000 (two hundred million rupiah).Therefore,Crypto Currency or Virtual Currency has a legal foundation to prohibit its use as the payment tool within Indonesia jurisdiction. 
On February 1st, 2018, market capitalization of digital assets reached USD520 billion.The amounts of digital assets circulating today are 1508 cryptos, where Bitcoin, Ethereum, Ripple, Bitcoin Cash and Cardona are at the top five based on the amount of market capitalization.Price is set by the market based on the law of demand and supply.

Crypto currencies represent multiple perspectives, both of which imply a positive or negative view.As a subjective view of the author, the current crypto-based investment is likely less stable.Indeed, the existence of large demand-supply indicates that it brings a strong economic movement. The conclusion to draw is that it still deserves to be used as an investment commodity, with limited and secondary values.

One of the most relevant ways to improve the scalability of crypto currency is achieving regulator support, i.e. Bank Indonesia. Hitherto, regulators are still exploring the possibilities that blockchain can generate. The potential is large, the proof still continues to be a challenge for the enthusiasts.Convincing an investment is not the wrong thing since each investment always has risks.For now, the risk of crypto currency investment is quite big with a variety of possibilities in market share.

\section{Literature Review}

The author uses the United States as a comparison for this case study because they are successful in applying regulation and granting legal status of Digital Assets as a Commodity.The United States managed to maintain the growth of Digital Asset ecosystem and are protected from the illegal use of Digital Assets such as for money laundering or terrorism financing by listing all transactions made by their people.

\subsection{Bitcoin by the Experts}

- (Golumbia, 2017): Bitcoin thrives after the capital market crisis in 2007/2008 which triggered a crisis of confidence in the Government and financial institutions in managing the fiat money system.

- (Srokosz and Kopyğciaĕski, 2015) Legal treatment for Bitcoin in each country is determined by a common law or civil low.In the United States, Bitcoin is seen as a public currency and classified as thelegal payment tool.In Europe,with the civil rights law system, it is classified into a private property right as securities and not recognized as the legal payment tool.

- (Baur, Hong and Lee, 2015) Users treat Bitcoin as an investment instrument. Therefore, it has no impact on monetary risk and economic stability.

\subsection{Considerations to Manage Digital Assets}

US Government Rules that can be used as a reference in regulating Digital Assets:

- IRS Notice 2014/21

- Tax Increase Prevention and Reconciliation Act 2005

- The Financial Crimes Enforcement Network (Fin Cen)

- Electronic Fund Transfer Act

Legal Rules that can be used in Indonesia:(Law of the Republic of Indonesia Number 10 Year 2011 on Amendments to Law Number 32 Year 1997 on Commodity Futures Trading, 2011). 


\section{Methodology}

This research uses literature study research by looking for theory reference and relevant scientific journals withcases or problems found.Theory reference is obtained though literature study serve as basic foundationand main instrument in conducting research. The objective of this study is to see the potential of Digital Crypto Asset, whether it can be applied in the Digital Assets only, or even it will be an Effect or Commodity in the future.

\section{Results And Conclusions}

\subsection{Effector Crypto Security}

Can Crypto can be considered as Securities or Investment Instrument in Indonesia?

The Law No. 8/1995 on Capital Markets defines Securities as Marketable Securities, namely: Acknowledgement of indebtedness, Commercial Paper, Shares, Obligations, Debt Securities, Statement of Collective Investment Contracts, Futures Contracts on Securities and any Derivatives of Securities. The Law No.40/2007 on Limited Liability Companies States that Shareholders have voting rights in the GMS and are entitled to a Dividend.The Law No.37/2004 on Bankruptcy and PKPU states that Securities or Commercial Paper Holder is a creditor who can apply for bankruptcy for Debitorto the Head of Court. The Crypto product owner does not have voting rights and dividends and cannot bother crypto miners. If Crypto is considered as Securities, there is no Legal Basis as the legal law.

\subsection{Commodity or Crypto Asset}

Can Crypto be considered as Commodity or Digital Asset in Indonesia ?

The Law No.10/2011 as Legislative Update of the Law No.32/1997 on Commodity

Futures Trading: Commodities are all goods, services, rights and other interests, and any Derivatives of Commodities, which may be traded and subject to Futures Contracts, Shariah Derivatives Contracts and/or other Derivative Contracts. The Law No.7/2014 on Trade: Trade is the order of activities related to transactions of Goods and/or Services.Goods can be tangible or intangible objects.Trading through Electronic Systems is a Trade in which transactions are made through the use of electronic devices and procedures.Crypto products as a commodity of intangible goods that can be traded have the legal basis as the legal law for trading through electronic systems.

\subsection{Benefits of Crypto Commodity}

- Improving Efficiency, Effectiveness and Production Capacity in the Era of the Industrial Revolution 4.0.

- Potentially accelerating and increasingthe trading volume of MSME sector through Global E-Commerce.

- Increasing potential tax revenues

- Improving the ability of the State Authority to monitor money laundering and terrorism crime transactions (Pseudonymous)

- Minimizing Economic Deadweight loss 


\subsection{Approach of Tax With drawal from Digital Asset Trading}

- Declaringits own Capital-Gain which is earned basedon everyone's income rate.This method has weaknesses in terms of supervision and high frequency of buying and selling Digital Asset in a day. Therefore, it is not effective in terms of implementation.

- Making final tax arrangement of trading transaction of Digital Asset as well as in stock buying and selling transactions, where taxes are levied directly by the industry. Therefore, it is easier to supervise.

- Simulation of tax revenue on the Digital Assets trading: Crypto trading in Indonesia reaches 1 Trillion Rupiah per Industry per day.Ifwe use the tax rate of stock exchange i.e. $0.1 \%$ for each trading transaction, there is potential for tax income for the country of 1 Billion Rupiah per day or a total of 365 billion Rupiah from each Industry in addition to corporate income tax.

\subsection{The Importance Of Domestic Regulation For Risk Mitigation}

- Block Chain protocols are very secure, but Digital Asset Exchange and Digital Asset Wallet industries are at risk from cyber-attacks. Therefore, industry-specific Standardization is required to ensure that every domestic industry implements high security standards.

- The standardization of KYC and AML in the Digital Asset Exchange Industry will help mitigate money laundering and criminal transactions with Crypto. Therefore, the transactions can be tracked using the Block Chain protocol and identified through data that has Digital Asset Exchange.

- The adoption of regulations to monitor transactions in the Digital Asset Exchange Industry will also help ensure that the price formation process on the Exchange is free of artificial price formation and Exchange can certainly act neutral in the price formation process.

\section{Conclusion}

- Crypto Currency can not be used as a means of payment and tools to trade goods and services in Indonesia.

- Crypto Asset or Virtual Currency has a legal basis to prohibit its use as a means of payment within the jurisdiction of Indonesia.

- Virtual Currency remains eligible to be an investment commodity, with limited and secondary value.

- There is no Legal Foundation as a legal law that can be the basis for making Crypto Asset as Securities or Securities.

- In Indonesia Crypto Asset to serve as a commodity of intangible goods that can be traded has a legal basis as a legal law for trading through electronic systems.

- Virtual Currency has the potential contributor of tax revenue that large enough for the state of Indonesia.

\section{References}

[1] Baur, D. G., Hong, K. and Lee, A. D. (2015) ‘Bitcoin: Currency or Investment?’, SSRN 
Electronic Journal. doi: 10.2139/ssrn.2561183.

[2] Golumbia, D. (2017) 'The Politics of Bitcoin: Software as Right-wing Extremism, by David Golumbia', Journal of Cultural Economy, 10(5), pp. 474-484. doi: 10.1080/17530350.2017.1322997.

[3] Law of the Republic of Indonesia Number 10 Year 2011 on Amendments to Law Number 32 Year 1997 on Commodity Futures Trading (2011) Undang-Undang. Available

https://drive.google.com/file/d/1g5FWhPkI1KzHPAy7zSovGlzPApOWcHnZ/view (Accessed: 22 January 2019).

[4] Law of The Republic of Indonesia Number 7 Year 2011 (2011). Available at: http://www.flevin.com/id/lgso/translations/Laws/Law No. 7 of 2011 on Currency (MoF).pdf (Accessed: 7 January 2019).

[5] Srokosz, W. and Kopyğciaěski, T. (2015) 'Legal and Economic Analysis of the Cryptocurrencies Impact on the Financial System Stability', Journal of Teaching and Education, 04(02), pp. 2165-6266. 